\title{
Identification of functionally important acidic residues in transducin by group-specific labeling
}

\author{
ANA KOSOY ${ }^{1 *}$, CAROLINA MÖLLER $^{1 * *}$, DEISY PERDOMO $^{2}$ and JOSÉ BUBIS ${ }^{2}$ \\ ${ }^{1}$ Departamento de Química, Universidad Simón Bolívar, Caracas, Venezuela \\ *Present address: Cancer Center, Mount Sinai Medical School, One Gustave L. Levy Place, Box 1020, \\ New York, NY 10029, U.S.A. \\ **Present address: Florida Atlantic University, 777 Glades Road, Boca Raton, FL 33431-0991, U.S.A. \\ ${ }^{2}$ Departamento de Biología Celular, Universidad Simón Bolívar, Caracas, Venezuela
}

\begin{abstract}
Transducin (T), a GTP-binding protein involved in phototransduction of rod photoreceptor cells, is a heterotrimer arranged as two units, the $\alpha$-subunit $\left(\mathrm{T}_{\alpha}\right)$ and the $\beta \gamma$-complex $\left(\mathrm{T}_{\beta} \gamma\right)$. The role of the carboxyl groups in $\mathrm{T}$ was evaluated by labeling with N, N'-dicyclohexylcarbodiimide (DCCD) and 1-ethyl 3-(3-dimethylaminopropyl) carbodiimide (EDC). Only a minor effect on the binding of $\beta, \gamma$-imido guanosine 5 '-triphosphate (GMPpNp) to T was observed in the presence of the hydrophobic carbodiimide, DCCD. Similarly, the GMPpNp binding activity of the reconstituted holoenzyme was not significantly affected when $\mathrm{T}_{\alpha}$ was combined with DCCD-treated $\mathrm{T}_{\beta \gamma}$. However, the binding of guanine nucleotides to the reconstituted $\mathrm{T}$ was $\sim 50 \%$ inhibited when DCCD-labeled T $\alpha$ was incubated with $\mathrm{T}_{\beta \gamma}$. In contrast, treatment of $\mathrm{T}$ with the hydrophilic carbodiimide, EDC, completely impaired its GMPpNp-binding ability. EDC-modified T was incapable of interacting with illuminated rhodopsin, as determined by sedimentation experiments. However, rhodopsin only partially protected against the inactivation of T. Additionally, analyses of trypsin digestion patterns showed that fluoroaluminate was not capable of activating the EDC-labeled T sample. The function of the reconstituted holoenzyme was also disrupted when EDC-modified $\mathrm{T}_{\alpha}$ was combined with $\mathrm{T}_{\beta \gamma}$, and when EDC-treated $\mathrm{T}_{\beta \gamma}$ was incubated with $\mathrm{T}_{\alpha}$.
\end{abstract}

Key terms: Chemical modification; G-protein-coupled signaling; group-specific labeling; transducin; visual process.

\section{INTRODUCTION}

Guanine nucleotide binding proteins (Gproteins) are heterotrimers composed of $\alpha$ , $\beta$-, and $\gamma$-subunits, which activate or inhibit many enzymes and channels as a response to signals generated by transmembrane receptors. In their inactive state, G-proteins form membrane-associated entities in which GDP is tightly bound to the $\alpha$-subunit. Upon activation, conformational changes catalyze the GTP/GDP exchange on the Gprotein, resulting in the dissociation of the $\alpha$-subunit bound to GTP, from the $\beta \gamma$ complex. Acting together or independently, both species may regulate the activity of several protein effectors. The basal state is restored when specific GTPase-activating proteins stimulate the intrinsic GTPase activity of the GTP-bound $\alpha$-subunit. Following GTP hydrolysis, the $\alpha$-subunit bound to GDP reassociates with the $\beta \gamma$ complex. Consequently, the reconstituted inactive G-protein is primed for a new cycle.

Vision in retinal rods is a typical example of a G-protein-coupled signaling system (Pugh et al., 1999). Here, signal transduction is initiated by the photoninduced isomerization of the chromophore 11-cis retinal bound to the photoreceptor protein rhodopsin (R), to all-trans-retinal. Structural changes in $\mathrm{R}$ lead to an active

Corresponding author: José Bubis, Laboratorio de Química de Proteínas, Departamento de Biología Celular, División de Ciencias Biológicas, Universidad Simón Bolívar, Apartado 89.000, Valle de Sartenejas, Baruta, Caracas 1081-A, Venezuela. Telephone: (58-212) 906-4219 - Fax: (58-212) 906-3064 - e-mail: jbubis@usb.ve 
intermediate, metarhodopsin II, which stabilizes its interaction with the retinal Gprotein transducin ( $\mathrm{T}$ ) and activates it. Photoexcited $\mathrm{R}\left(\mathrm{R}^{*}\right)$ catalyzes the exchange of GDP for GTP on T, which triggers conformational changes in the protein that result in dissociation of its GTP-bound $\alpha$ subunit $\left(\mathrm{T}_{\alpha}\right)$ from the $\beta \gamma$-complex $\left(\mathrm{T}_{\beta \gamma}\right) . \mathrm{T}_{\alpha^{-}}$ GTP, in turn, activates a potent cGMP phosphodiesterase (cGMP-PDE). The reduction in intracellular cGMP concentration causes cation-specific cGMP-gated channels to close, leading to the hyperpolarization of the rod cell membrane and to the generation of a neuronal signal.

Protein chemistry strategies have been used to identify functional residues in $\mathrm{T}$ (Ho and Fung, 1984; Reichert and Hofmann, 1984; Hofmann and Reichert, 1985; Hingorani and Ho, 1987; Dhanasekaran et al., 1988; Yang et al., 1999). Both the photodependent binding of $\mathrm{T}$ to $\mathrm{R}$ and the $\mathrm{T}$ guanine nucleotide exchange reaction were affected by chemical modification of $\mathrm{T}$ with various sulfhydryl-specific compounds (Ortiz and Bubis, 2001). In particular, the alkylation of $\mathrm{T}$ with iodoacetic acid identified $\mathrm{Cys}_{347}$ of $\mathrm{T}_{\alpha}$ as a functionally-important amino acid in the protein (Bubis et al., 2001). A series of reagents that specifically modify lysyl residues have also been shown to hinder the light-dependent guanine nucleotide binding of $\mathrm{T}$ (Bubis et al., 1995). Furthermore, cross-linking techniques have been utilized to identify sites involved in intra- and inter-subunit contacts in T (Bubis and Khorana, 1990; Millán and Bubis, 2002) and to analyze the interactions between $\mathrm{T}$ and cGMPPDE (Hingorani et al., 1988; Clerc et al., 1992). Recently, the guanine nucleotidebinding site of $\mathrm{T}$ was also examined by affinity labeling with pyridoxal 5'phosphate (Jaffé and Bubis, 2002). To continue the studies on the structurefunction of $\mathrm{T}$, we have performed chemical modification experiments with N, N'dicyclohexylcarbodiimide (DCCD) and 1ethyl 3-(3-dimethylaminopropyl) carbodiimide (EDC) to probe for $T$ functional acidic amino acids.
METHODS

\section{Materials}

Bovine eyes were obtained from the nearest slaughterhouse (Matadero Caracas, C.A.). Retinae were extracted in the dark under red light and were maintained frozen at -70 ${ }^{\circ} \mathrm{C}$. Reagents were purchased from the following sources: $\beta, \quad \gamma$-imido- $[3 \mathrm{H}]$ guanosine 5 '-triphosphate $([8-3 \mathrm{H}]$ GMPpNp) (15.6 Ci/mmol), Amersham; [8, 5-3H] GTP (15 Ci/mmol), American Radiolabeled Chemicals Inc.; EDC, Pierce; DCCD, aspartic acid, glutamic acid, tosylphenyl alanyl chloromethyl ketone (TPCK)-treated trypsin, Sigma; DEAE Sepharose, Pharmacia; blue agarose, Bethesda Research Laboratories; $\omega$-amino octyl agarose, ICN Biomedicals. All other chemical compounds were analytical grade.

\section{Preparation of rod outer segments and} washed membranes

Rod outer segments (ROS) were isolated from frozen bovine retinae by flotation and subsequent centrifugation on discontinuous sucrose gradients (Bubis, 1998). Darkdepleted and urea-washed ROS membranes were prepared as described by Baehr et al. (1979) and Shichi and Somers (1978), respectively. ROS membranes, darkdepleted ROS membranes, and urea-washed ROS membranes were stored in the dark, at $-70{ }^{\circ} \mathrm{C}$. R concentration was calculated from its UV/visible absorption spectra, using the molar extinction coefficient of the protein (Wald and Brown, 1953).

\section{Purification of $T$ and its subunits}

$\mathrm{T}$ was purified from ROS membranes prepared under room light, using anionexchange chromatography on DEAE Sepharose (Bubis, 1995). $\mathrm{T}_{\alpha}$ and $\mathrm{T}_{\beta \gamma}$ were isolated to homogeneity by chromatography in tandem through blue agarose followed by $\omega$-amino octyl agarose (Bubis, 1995). $\mathrm{T}_{\alpha}$-GTP $\gamma \mathrm{S}$ was prepared as described by Fung (1983). 


\section{Binding of guanine nucleotides to $T$}

The guanine nucleotide binding activity of $\mathrm{T}$ was measured by Millipore filtration using $[3 \mathrm{H}]$ GTP or a nonhy drolyzable analog of GTP, $\left[{ }^{3} \mathrm{H}\right]$ GMPpNp. The binding reaction was carried out in Buffer A [50 $\mathrm{mM}$ Tris- $\mathrm{HCl}$ ( $\mathrm{pH} 7.5$ ), $5 \mathrm{mM}$ magnesium acetate, $100 \mathrm{mM} \mathrm{NaCl}$ and $5 \mathrm{mM} \beta$ mercaptoethanol] containing $0.1 \mu \mathrm{M} \mathrm{R}$ (as dark-depleted or urea-washed ROS membranes), 0.15-0.2 $\mu \mathrm{M}$ of native or reconstituted $\mathrm{T}$, and a fixed concentration of [33] GTP or GMPpNp $(0.2 \mu \mathrm{M})$ (Bubis et al., 1993; Ortiz and Bubis, 2001). Blanks were measured in the absence of $\mathrm{T}$ and were subtracted from all the values. In all cases, the average value resulting from triplicate determinations was reported.

Modification of the acidic residues of $T, T_{\alpha}$ and $T_{\beta \gamma}$ with DCCD or EDC

Stock solutions of DCCD and EDC were freshly prepared in acetonitrile or water, respectively. $\mathrm{T}(0.2 \mu \mathrm{M})$ was incubated for $1 \mathrm{~h}$, at $4{ }^{\circ} \mathrm{C}$, with various concentrations of DCCD or EDC $(0-40 \mathrm{mM})$ in $50 \mathrm{mM}$ Pipes (pH 6.2) and $30 \mathrm{mM}$ magnesium acetate. The function of the modified $\mathrm{T}$ was assessed, and its remaining light-dependent $\left[{ }^{3} \mathrm{H}\right]$ GTP or $\left[{ }^{3} \mathrm{H}\right]$ GMPpNp binding activity was determined as described above. The kinetics of modification of T by DCCD or EDC was examined by incubating T with 5 $\mathrm{mM}$ of either cabodiimide in the same buffer. The reactions were terminated at designated time intervals $(0-60 \mathrm{~min})$ by the addition of $30 \mathrm{mM}$ aspartic acid and $20 \mathrm{mM}$ B-mercaptoethanol ( $\mathrm{pH}$ 6.2), and the remaining guanine nucleotide binding activity of the treated protein was determined. In some experiments, reactions were terminated with $20 \mathrm{mM} \quad \beta-$ mercaptoethanol and $30 \mathrm{mM}$ of either glutamic acid or acetic acid ( $\mathrm{pH}$ 6.2). Both $\mathrm{T}_{\alpha}$ and $\mathrm{T}_{\beta \gamma}(0.15 \mu \mathrm{M})$ were also individually reacted with $5 \mathrm{mM}$ DCCD or EDC in a similar fashion. After terminating the reaction, they were reconstituted with 0.15 $\mu \mathrm{M}$ of the complementary untreated unit to reform the holoenzyme, and assayed for $\left[{ }^{3} \mathrm{H}\right]$ GTP binding.
Interaction assay between EDC-modified $T$ and $R^{*}$

$\mathrm{T}(4 \mu \mathrm{M})$ was incubated with $5 \mathrm{mMEDC}$ in 50 $\mathrm{mM}$ Pipes (pH 6.2) and $30 \mathrm{mM}$ magnesium acetate. Following $1 \mathrm{~h}$ incubation at $4{ }^{\circ} \mathrm{C}$, the reaction was terminated with $20 \mathrm{mM} \mathrm{B-}$ mercaptoethanol and $30 \mathrm{mM}$ aspartic acid (pH 6.2). Parallel experiments in which T was incubated with buffer alone or with EDC previously titrated with $20 \mathrm{mM} \beta$ mercaptoethanol and $30 \mathrm{mM}$ aspartic acid (pH 6.2) were included as controls. At this step, $\mathrm{T}$ was denominated $\mathrm{T}$ (Asp/Glu-X), where $\mathrm{X}=$ hydrogen or the labeling group. An aliquot of urea-washed ROS membranes containing $3.5 \mu \mathrm{M}$ R was mixed with $\mathrm{T}$ (Asp/ Glu-X) $(2.4 \mu \mathrm{M})$ in an isotonic solution [5 $\mathrm{mM}$ Tris-HCl (pH 7.5), $100 \mathrm{mM} \mathrm{NaCl}, 5 \mathrm{mM}$ magnesium acetate and $5 \mathrm{mM}$ Bmercaptoethanol]. To allow the formation of the transducin-photoactivated rhodopsin complex $\left(\mathrm{T}: \mathrm{R}^{*}\right)$, the mixture was cooled on ice, kept in the dark for $10 \mathrm{~min}$, then illuminated for $1 \mathrm{~min}$ with bright light and held for $1 \mathrm{~h}$ under room light, at $4{ }^{\circ} \mathrm{C}$. After a first centrifugation step (30 min at 40,000 rpm, RP120AT-203 fixed angle rotor, Sorvall RCM120 microultracentrifuge) the supernatant (S-ISO) was carefully removed. The bleached pellet was washed with hypotonic buffer [5 $\mathrm{mM}$ Tris- $\mathrm{HCl}(\mathrm{pH}$ 7.5), $5 \mathrm{mM}$ magnesium acetate and $5 \mathrm{mM}$ ß-mercaptoethanol] and centrifuged as before to remove residual soluble proteins. The supernatant (S-HYPO) was saved for subsequent analyses, while the pellet was washed with $150 \mu \mathrm{M}$ GTP in hypotonic buffer (Pr-GTP). The Pr-GTP was then centrifuged, and both the resultant supernatant (S-GTP) and the resuspended final pellet (Pf) were stored for later examination. Aliquots of $\mathrm{T}$ (Asp/Glu-X), S-ISO, S-HYPO, Pr-GTP, SGTP and Pf were analyzed by sodium dodecyl sulfate (SDS)-polyacrylamide gel electrophoresis (SDS-PAGE) and Western blot.

Assay of T functionality in the T:R* complex incubated with EDC

$\mathrm{T}(1.4 \mu \mathrm{M})$ was incubated with darkdepleted ROS membranes $(5.6 \mu \mathrm{M} \mathrm{R})$ for 1 $\mathrm{h}$, at $4{ }^{\circ} \mathrm{C}$, under light in order to form the 
$\mathrm{T}: \mathrm{R} *$ complex. This suspension was centrifuged to remove residual free $\mathrm{T}$ (30 min at 40,000 rpm, RP120AT-203 fixed angle rotor, Sorvall RCM120 microultracentrifuge), and the pellet was resuspended in $50 \mathrm{mM}$ Pipes $(\mathrm{pH} \mathrm{6.2)}$ and $30 \mathrm{mM}$ magnesium acetate, containing 5 $\mathrm{mM}$ EDC. Following incubation on ice for 1 $\mathrm{h}$, the reaction was terminated with $20 \mathrm{mM}$ B-mercaptoethanol and $30 \mathrm{mM}$ aspartic acid ( $\mathrm{pH}$ 6.2). This incubation was performed at $4^{\circ} \mathrm{C}$ in order to maintain the metarhodopsin II photointermediate. Control experiments were carried out in which the pellet containing the $\mathrm{T}: \mathrm{R}^{*}$ complex, was either incubated with buffer or treated with EDC quenched with $20 \mathrm{mM} \quad \beta$-mercaptoethanol and $30 \mathrm{mM}$ aspartic acid $(\mathrm{pH} 6.2)$. This sample was denominated Pr (Asp/Glu-X), where $\mathrm{X}=$ hydrogen or the labeling group. The treated membranes were initially washed with hypotonic buffer to release free EDC and residual soluble proteins. After centrifugation, we obtained the S-1 supernatant and the corresponding pellet (Pr). This wash was repeated to yield the S2 supernatant. The release of $\mathrm{T}$ was examined by washing the resulting pellet with hypotonic buffer containing $150 \mu \mathrm{M}$ GTP. Centrifugation of the GTP resuspended pellet (Pr-GTP) yielded a supernatant (S-GTP) and a final pellet (Pf). Aliquots of $\operatorname{Pr}$ (Asp/GluX), S-1, Pr, S-2, S-GTP and Pf were analyzed by SDS-PAGE and Western blot.

\section{Limited trypsin proteolysis of EDC modified-T in the presence of fluoroaluminate}

Fluoroaluminate $\left(30 \mu \mathrm{M} \mathrm{AlCl}{ }_{3}\right.$ and $10 \mathrm{mM}$ $\mathrm{NaF}$ ) was added to $15 \mu \mathrm{g}$ of untreated or EDC-modified T. Following an incubation for $1 \mathrm{~h}$ on ice, the samples were digested with TPCK-treated trypsin using a ratio of 1:20 (w/w) protease:T. Aliquots containing $5 \mu \mathrm{g}$ of $\mathrm{T}$ were withdrawn at various time intervals (0-60 $\mathrm{min})$ and digestions were terminated by the addition of SDS-PAGE sample buffer (Laemmli, 1970). Subsequently, the samples were boiled for $20 \mathrm{~min}$, and the protein fragments were resolved by SDS-PAGE. The gels were then either stained or analyzed by Western blotting as described below.

\section{Other procedures}

Protein concentration was measured according to Bradford (1976), using bovine serum albumin as protein standard. SDSPAGE was carried out on $1.5-\mathrm{mm}$ thick slab gels containing 10 or $15 \%$ polyacrylamide (Laemmli, 1970). Coomassie blue R-250 or silver nitrate was used for protein staining. For Western blot analyses, the proteins were electrotransferred from the gels to nitrocellulose filters (Towbin et al., 1979). For immunodetection, the filters were incubated with polyclonal antibodies against bovine $\mathrm{T}$ (dilution 1:1000), prepared in mice (Bubis et al., 1993). These antibodies preferentially recognize $T_{\alpha}$ but have some cross-reactivity with $\mathrm{R}$. The antigenically reacting polypeptides were then treated with alkaline phosphataseconjugated secondary antibodies against mouse $\mathrm{IgG}$, at a dilution of 1:5000. Finally, the bands were visualized with 5-bromo-4chloro-3-indolyl phosphate and nitro blue tetrazolium as substrates.

\section{RESULTS}

We used two different carbodiimides, EDC and DCCD, to chemically modify $\mathrm{T}$ and examine for functionally important acidic amino acids in the protein. EDC is a watersoluble compound that can be used to monitor solvent-accessible carboxyl groups in the protein. On the contrary, DCCD is a nonpolar carbodiimide that will partition into the hydrophobic environment of the protein.

Chemical modification of Asp and Glu residues preferentially occur at $\mathrm{pHs}$ below their corresponding $\mathrm{pK}_{\mathrm{a}} \mathrm{s}(\sim \mathrm{pH} 4)$. However, globular proteins will commonly denature at these low $\mathrm{pH}$ values. Since at $\mathrm{pH} 6.2$, proteins are generally stable and a certain proportion of their acidic amino acids are maintained in the protonated form, all labeling reactions of T with DCCD and EDC were performed at this $\mathrm{pH}$. We initially 
measured the effect of $\mathrm{pH}$ on the GMPpNp binding activity of $\mathrm{T}$. T guanine nucleotide binding activity was favored at $\mathrm{pH}$ 7.5-8.0, and only about $60 \%$ of the $\mathrm{T}$ functional activity remained at $\mathrm{pH} 6.2$ (data not shown). Additionally, the GMPpNp binding capability of $\mathrm{T}$ was fully restored when the $\mathrm{pH}$ of the reaction mixture was increased from 6.2 to 7.5 , using aliquots of $100 \mathrm{mM}$ Tris- $\mathrm{HCl}$ (pH 8.8) (data not included). Consequently, the $\mathrm{pH}$ of the carbodiimidetreated $\mathrm{T}$ samples was always augmented to 7.5 before measuring their corresponding guanine nucleotide binding activity.

As will be seen later, DCCD $(5 \mathrm{mM}) \mathrm{did}$ not have much effect on the GMPpNp binding activity of T. However, EDC ( 5 $\mathrm{mM}$ ) completely inactivated the protein. Several compounds were then explored for their capability of protecting against the inactivation of T by EDC. When $30 \mathrm{mM}$ of acetic acid, aspartic acid, or glutamic acid was pre-incubated with $5 \mathrm{mM}$ EDC previous to its addition to $\mathrm{T}$, all three reagents were capable of blocking the observed EDC inhibition in the GMPpNp binding activity of $\mathrm{T}$ (data not shown). Thus, subsequent carbodiimide reactions were terminated using $30 \mathrm{mM}$ aspartic acid.

The effect of different concentrations of DCCD and EDC on the binding of guanine nucleotides to $\mathrm{T}$ is illustrated in Figure $1 \mathrm{a}$. When $\geq 5 \mathrm{mM}$ EDC was added to $\mathrm{T}$, we observed a $95 \%$ inhibition of its lightdependent GMPpNp binding capacity (Fig. 1a). In contrast, a minor effect on $T$ function was shown when the protein was incubated with DCCD. As seen in Figure $1 \mathrm{a}$, a maximum of 20-25\% inhibition in $\mathrm{T}$ function was obtained when the protein was incubated with high concentrations of DCCD $(\geq 40 \mathrm{mM})$. Similar results were observed when $[3 \mathrm{H}]$ GTP was used as the nucleotide binding ligand (data not shown). Additionally, incubation of $\mathrm{T}$ with up to $8 \%$ acetonitrile, the highest concentration present in the experiments where various amounts of DCCD were used, did not produce any effect on the functional activity of the protein (data not shown).

The time course of the modification reaction of $\mathrm{T}$ by EDC or DCCD was also determined. At the corresponding time intervals, the reactions were terminated by the addition of $30 \mathrm{mM}$ aspartic acid and assayed for GMPpNp binding. Figure $1 \mathrm{~b}$ shows the kinetics of the light-dependent GMPpNp binding activity of EDC- and
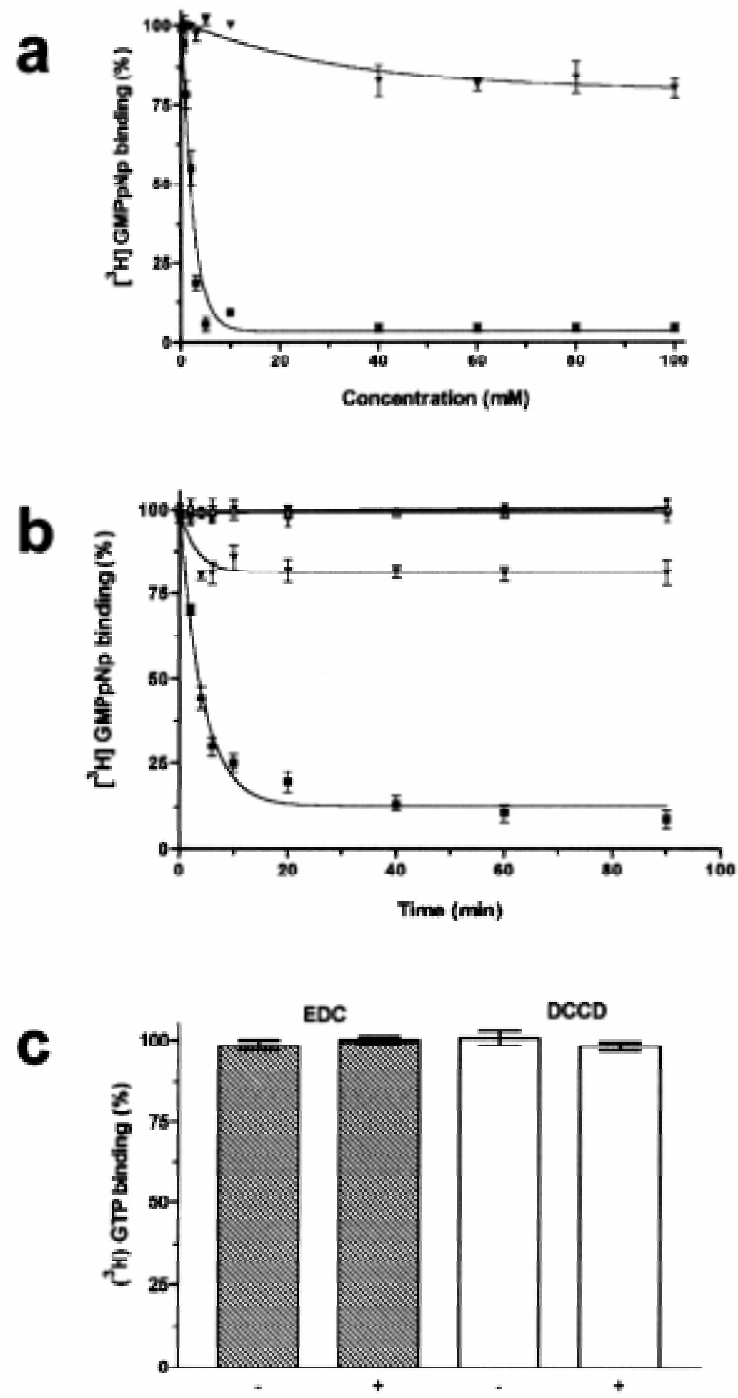

Figure 1.- Effect of DCCD and EDC on the functional activities of $\mathrm{T}$ and $\mathrm{R}$. (a) $\mathrm{T}$ was incubated with various concentrations of DCCD $(\boldsymbol{\nabla})$ or EDC $(\boldsymbol{\nabla})$, and its remaining light-dependent GMPpNp binding activity was assayed in the presence of R. (b) T was treated with $5 \mathrm{mM}$ EDC ( $\mathbf{\square}), 5 \mathrm{mM}$ $\operatorname{DCCD}(\boldsymbol{\nabla}), 5 \mathrm{mM}$ EDC previously titrated with $30 \mathrm{mM}$ Asp $(\triangle), 5 \mathrm{mM}$ DCCD previously titrated with $30 \mathrm{mM}$ Asp $(\diamond)$, or with just buffer $($ ). At the indicated time intervals, the reactions were terminated with $30 \mathrm{mM}$ Asp and assayed for its $\mathrm{R}^{*}$-dependent GMPpNp binding activity. (c) $\mathrm{R}$, in the form of urea-washed ROS membranes, was treated (+) or not (-) with $5 \mathrm{mM}$ DCCD (white bars) or EDC (dashed bars). Following incubation for $1 \mathrm{~h}$, at $4{ }^{\circ} \mathrm{C}$, the reactions were terminated with $30 \mathrm{mM}$ Asp, and the samples were used to induce the photodependent GTP binding activity of T. 
DCCD-modified T. More than $90 \%$ of the T guanine nucleotide binding ability was inhibited following $20 \mathrm{~min}$ of incubation with $5 \mathrm{mM}$ EDC. However, only a $20 \%$ inactivation of DCCD-modified T was seen following $90 \mathrm{~min}$ incubation with the hydrophobic carbodiimide (Fig. 1b). On the basis of these results, we focused our attention on the modification of $\mathrm{T}$ acidic residues with EDC.

Parallel labeling experiments using $\mathrm{R}$ were also carried out to examine the effect of EDC or DCCD on its ability to activate T. As shown in Figure 1c, when $R$ was incubated with $5 \mathrm{mM}$ of either EDC or DCCD, the treatment did not affect its capacity to catalyze the light-induced guanine nucleotide exchange reaction in $\mathrm{T}$.

$\mathrm{T}$ samples incubated with $5 \mathrm{mM}$ EDC or left unincubated were separated by SDSPAGE. EDC-treated T showed a decrease in the polypeptide bands corresponding to $\mathrm{T}_{\alpha}$ and $\mathrm{T}_{\beta}$, with a concomitant appearance of high molecular mass species (> $200 \mathrm{kDa})$ (Fig. 2). Then the EDC-induced crosslinking of $\mathrm{T}$ subunits may be partially responsible for the functional inactivation of the protein.

The ability of EDC-modified T to interact with $\mathrm{R}^{*}$ was measured by the affinitybinding procedure described by Kühn (1980). EDC-modified T was incubated with urea-washed ROS membranes under room light, and various washes were performed as described under Materials and Methods. After centrifugation, the components of each washing step were separated by SDSPAGE and visualized by silver staining. Comparable gels were electrotransferred to nitrocellulose filters and immunoanalyzed with polyclonal antibodies against T. Since the antibodies that were used primarily recognized $\mathrm{T}_{\alpha}$, but showed some cross-reactivity with $\mathrm{R}$ (Bubis et al., 1993), the samples were extensively boiled prior to the electrophoresis in order to induce the formation of high molecular weight $\mathrm{R}$ aggregates. The unmodified $\mathrm{T}$ behaved as expected (Fig. 3a and b, $\mathrm{T}_{\text {CONTROL }}$ ). After reconstitution, approximately $60-80 \%$ of the original $\mathrm{T}$ became tightly bound to the bleached, washed ROS membranes (Pr-GTP). Isotonic
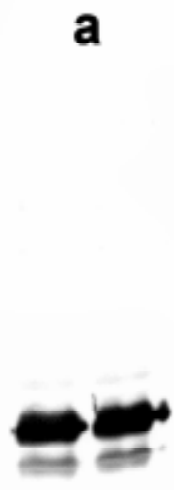

b
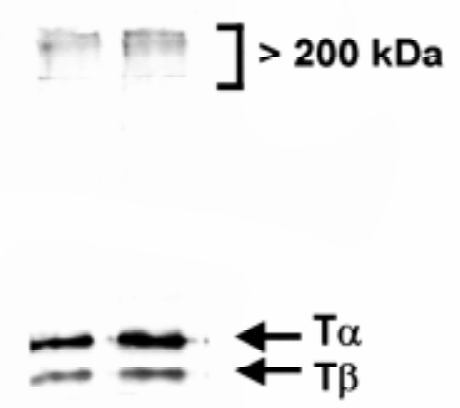

Figure 2.- Cross-linking of T by EDC. T was incubated with buffer alone (a) or with $5 \mathrm{mM} \operatorname{EDC}(\mathrm{b})$, for $1 \mathrm{~h}$, at $4{ }^{\circ} \mathrm{C}$. Following the addition of $30 \mathrm{mM}$ Asp, the various $\mathrm{T}$ samples were electrophoresed on a $10 \%$ polyacrylamide gel in the presence of SDS.

and hypotonic washing steps (S-ISO and SHYPO) were performed to eliminate the excess of $\mathrm{T}$, which did not specifically interact with $\mathrm{R}^{*}$. The bound $\mathrm{T}$ then partially dissociated from the membranes following incubation with GTP (S-GTP). Since five extractions with buffer containing GTP were generally required to entirely remove $T$ from illuminated ROS membranes (data not included), some of the bound $\mathrm{T}$ remained attached to the Pf fraction following one wash with this solution. A second control experiment containing T incubated with EDC that had been titrated with $30 \mathrm{mM}$ aspartic acid showed an electrophoretic pattern that was identical to the untreated $\mathrm{T}$ (data not shown). As illustrated in Figure 3 ( $a$ and $b$, $\mathrm{T}_{\mathrm{EDC}}$ ), the modification of $\mathrm{T}$ with $\mathrm{EDC}$ hindered its binding to $\mathrm{R}^{*}$ and the labeled protein was recovered in the supernatant following the first centrifugation (S-ISO). These results indicated that the residues labeled by EDC must be located in the $R$ binding site of $\mathrm{T}$.

$\mathrm{T}$ was incubated with dark-depleted ROS membranes under room light to form the $\mathrm{T}: \mathrm{R} *$ complex. $\mathrm{T}: \mathrm{R} *$ was then treated with EDC to assess whether $\mathrm{R} *$ was capable of protecting against the observed EDC inhibition in the guanine nucleotide binding activity of $\mathrm{T}$, and washes were performed to evaluate the ability of $\mathrm{T}$ of dissociating from these complexes in the presence of GTP. The components of these washes were 
separated by SDS-PAGE, and the from the ROS membranes in the untreated polypeptide pattern was visualized by silver T:R* complex (S-GTP) (Fig. 4a, Control). staining. Although some of the bound $\mathrm{T}$ As expected, the other control experiment remained attached to the $\mathrm{Pf}$ fraction in which $\mathrm{T}: \mathrm{R} *$ was incubated with EDC following one wash with the solution that was previously titrated with $30 \mathrm{mM}$ containing GTP, T was eluted with GTP aspartic acid showed the same pattern as

a

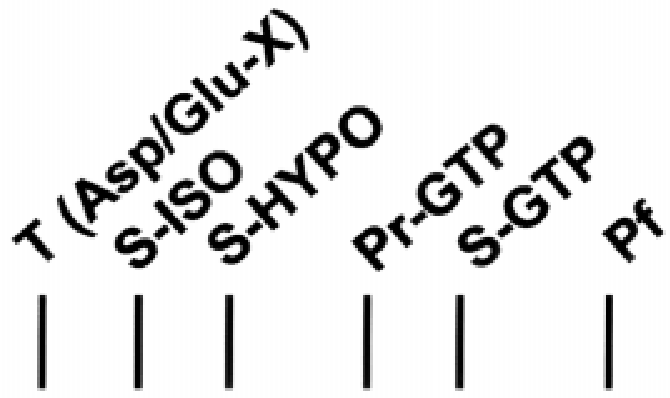

$\mathbf{T}_{\text {Control }}$

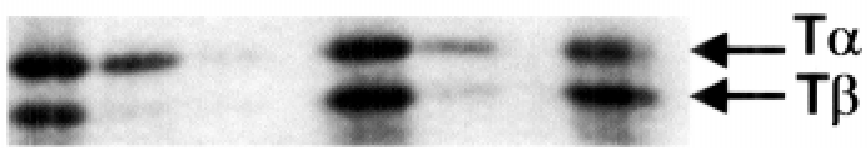

$\mathbf{T}_{\mathrm{EDC}}$

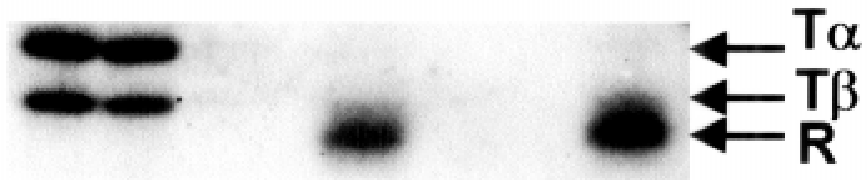

b

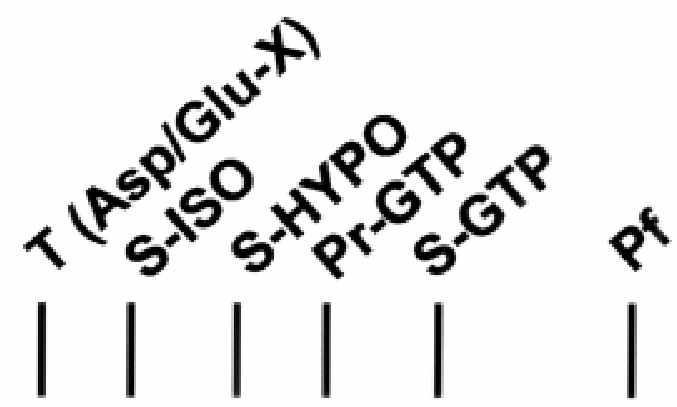

$\mathbf{T}_{\text {Control }}$

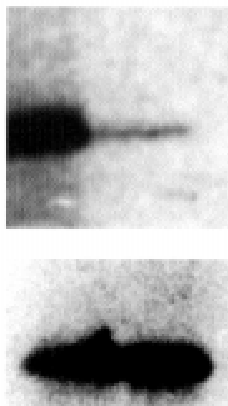

$\mathrm{T} \alpha$

$T_{\text {EDC }}$

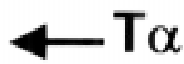

Figure 3.- Sedimentation assay of T or EDC-modified $\mathrm{T}$ in the presence of illuminated urea-washed ROS membranes. Samples of EDC-labeled or unlabeled T were incubated with photostimulated urea-washed ROS membranes. Following SDS-PAGE, the supernatants and pellets yielded by the sedimentation assay described under Materials and Methods were analyzed by silver staining (a) or by Western blot using polyclonal antibodies against $\mathrm{T}$ (b). The immunoblotted samples were boiled extensively previous to the electrophoresis separation. $\mathrm{T}_{\mathrm{CONTROL}}$, unlabeled $\mathrm{T} ; \mathrm{T}_{\mathrm{EDC}}$, EDC-modified $\mathrm{T}$. 
the untreated $\mathrm{T}: \mathrm{R} *$ sample (data not shown). The pattern for the EDC-treated $T: R^{*}$ complex was identical to both control samples (Fig 4a, EDC). T was liberated from the ROS membranes in the presence of GTP (S-GTP), which suggested that $\mathrm{R}^{*}$ protected against the inactivation of $\mathrm{T}$ by EDC and demonstrated that some of the residues modified by EDC must be located in the $\mathrm{R}$ binding site of the protein. Alternatively, $\mathrm{T}$ was immunologically detected following electrotransfer of the gels to nitrocellulose filters showing identical results (data not shown). However, when the GMPpNp binding activity of the EDC-treated T:R* sample was quantitatively determined, a $40-50 \%$ protection against the inactivation of $\mathrm{T}$ by

a

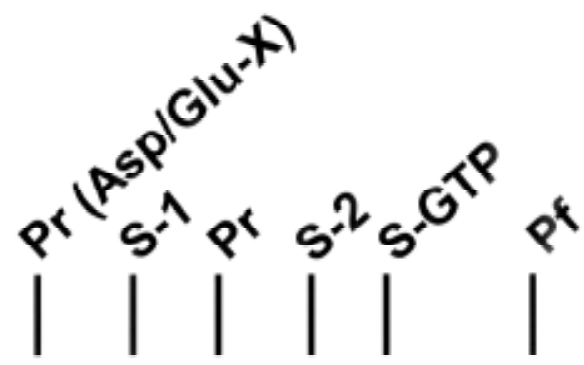

\section{Control}
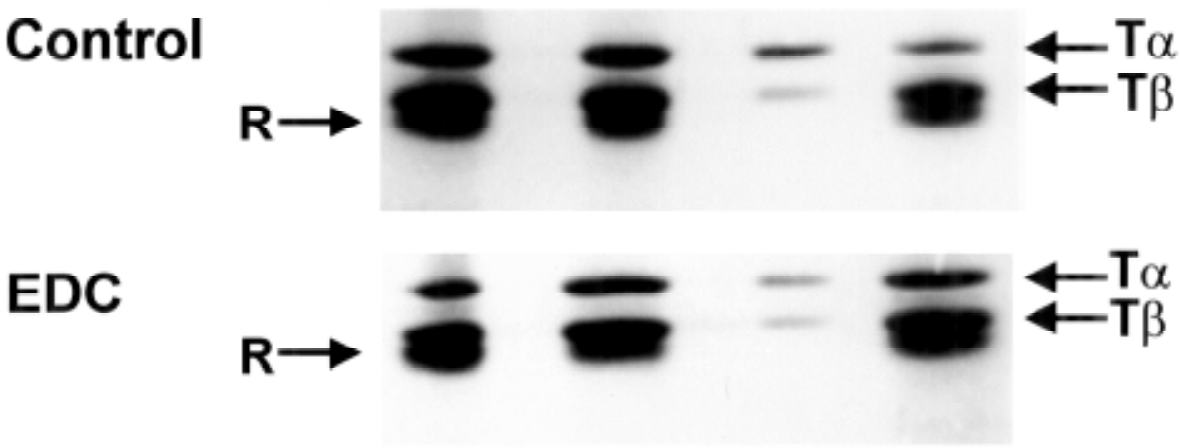

b

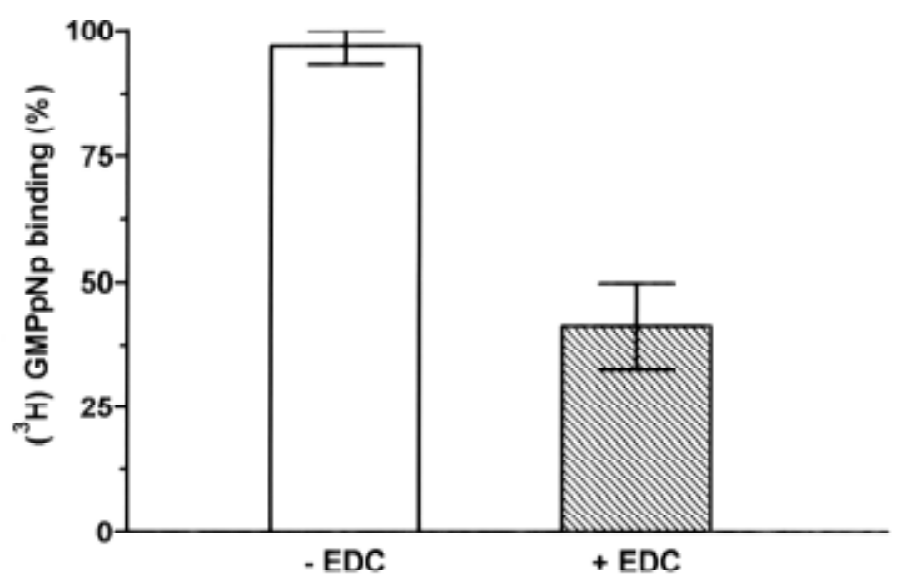

Figure 4.- T functionality in $\mathbf{T}: \mathbf{R}^{*}$ complexes treated with EDC. (a) T:R* complexes were incubated with or without EDC (EDC or Control, respectively). The supernatants and pellets obtained by the various washes were analyzed by SDS-PAGE, and the polypeptide bands were visualized by silver staining. (b) GMPpNp binding activity of T in T:R* complexes treated with EDC. An aliquot of the Pr (Asp/Glu-X) fraction obtained from $\mathrm{T}: \mathrm{R}^{*}$ complexes incubated with EDC was examined for its remaining GMPpNp binding activity (+ EDC). A sample of the corresponding fraction obtained from $\mathrm{T}: \mathrm{R}^{*}$ complexes incubated without EDC was included as a control experiment (- EDC). 
EDC was detected (Fig. 4b). These results showed that $\mathrm{R}^{*}$ only partially protected against the inhibition of $T$ by EDC and indicated that other functionally-important acidic residues were also labeled in $\mathrm{T}$ by the hydrophilic carbodiimide.

Two well-characterized conformations of $\mathrm{T}$ have been reported, the inactive GDPbound state and the active GTP-bound state (Hamm, 1998). Previous reports have clearly shown that tryptic digestions of inactive and active $\mathrm{T}_{\alpha}$ yielded dissimilar polypeptide patterns (Fung and Nash, 1983). Additionally, in the presence of GDP, $\mathrm{T}_{\alpha}$ incubated with fluoroaluminate existed as a structure in which the bound $\mathrm{AlF}_{4^{-}}$mimicked the $\gamma$-phosphate of GTP in its pentavalent transition state during hydrolysis (Sondek et al., 1994). Since activated $\mathrm{T}_{\alpha}$ and $\mathrm{AlF}_{4}$--bound $\mathrm{T}_{\alpha}$ produced identical protein fragments when incubated with trypsin (Bigay et al., 1985, 1987), protease protection assays of $\mathrm{T}$ in the presence of $\mathrm{AlF}_{4}$ - have been extensively used to study the light-independent activation of the protein (García et al., 1995; Natochin and Artemyev, 2000). Figure 5 shows the resulting tryptic polypeptide patterns obtained for untreated $\mathrm{T}$ and EDC-modified $\mathrm{T}$ in the presence of $\mathrm{AlF}_{4^{-}}$. Western blot analyses using anti- $\mathrm{T}$ polyclonal antibodies that preferentially recognized $\mathrm{T}_{\alpha}$ showed that trypsin-resistant fragments of $34 \mathrm{kDa}$ appeared when the untreated $\mathrm{T}$ sample was supplemented with $\mathrm{AlF}_{4}$ - (Fig. 5, Control $+\mathrm{AlF}_{4}$ ). However, no trypsin protection was observed when fluoroaluminate was added to the EDClabeled T sample (Fig. 5, EDC $\left.+\mathrm{AlF}_{4}\right)$. On the contrary, the resulting tryptic polypeptide profile, which contained bands of lower molecular weight $(23 \mathrm{kDa})$, was similar to the pattern obtained for the inactive T sample (Fig. 5, Control). When activated $\mathrm{T}_{\alpha}-\mathrm{GTP} \gamma \mathrm{S}$ was subjected to proteolysis with trypsin, the expected protection from extensive cleavage was observed and a band of $34 \mathrm{kDa}$ emerged (data not shown). These results indicated that $\mathrm{AlF}_{4^{-}}$was not capable of mimicking the transitional state of T in the EDC-labeled sample, suggesting that EDC was also modifying acidic residues located in or near the magnesium and guanine nucleotidebinding site of $\mathrm{T}$, or in the switch regions that undergo the conformational changes occurring during the activation of the protein. The formation of high molecular weight cross-linking aggregates following $\mathrm{T}$ incubation with EDC was again clearly seen, as illustrated in Figure $5(\mathrm{EDC}+$ $\left.\mathrm{A} \mathrm{F}_{4}\right)$. Although similar results were obtained when the gels were silver stained, the presence of tryptic polypeptides from $\mathrm{T}_{\beta}$ blurred and slightly buried the resulting fragments from $\mathrm{T}_{\alpha}$ (data not shown).

In order to explore the effect of DCCD and EDC on the individual functional units of $\mathrm{T}$, $\mathrm{T}_{\alpha}$ and $\mathrm{T}_{\beta \gamma}$ were isolated by chromatography in tandem through blue agarose followed by $\omega$-amino octylagarose (Bubis, 1995). As seen in Figure 6, DCCD did not affect $\mathrm{T}_{\beta \gamma}$, since DCCD-treated $\mathrm{T}_{\beta \gamma}$, when combined with intact $\mathrm{T}_{\alpha}$, maintain the GTP binding activity of the reconstituted holoenzyme. However, the guanine nucleotide binding activity of the reconstituted $\mathrm{T}$ was $40-50 \%$ inhibited when DCCD-modified $\mathrm{T}_{\alpha}$ was incubated with $\mathrm{T}_{\beta \gamma}$ (Fig. 6). On the other hand, a complete inhibition on the guanine nucleotide binding capability of the reconstituted holoenzyme was demonstrated when both EDC-modified $\mathrm{T}_{\alpha}$ was incubated with $\mathrm{T}_{\beta \gamma}$, and when EDC-treated $\mathrm{T}_{\beta \gamma}$ was combined with $\mathrm{T}_{\alpha}$ (Fig. 6). Similar results were observed when the time course of the modification reaction of $\mathrm{T}$ functional units by EDC or DCCD was determined. At the corresponding time intervals, the reactions were terminated by the addition of $30 \mathrm{mM}$ Asp and assayed for GTP binding following incubation with the missing unit to reform the holoenzyme. Although no effect on the functional activity of $\mathrm{T}_{\beta \gamma}$ was produced after 90 min of incubation with DCCD, approximately $50 \%$ inactivation on the lightdependent guanine nucleotide binding activity of the reconstituted $\mathrm{T}$ was obtained when DCCD-treated $\mathrm{T}_{\alpha}$ was combined with untreated $\mathrm{T}_{\beta \gamma}$, following 20 min incubation with the hydrophobic cabodiimide (data not included). In contrast, about $85-90 \%$ of the reconstituted $\mathrm{T}$ guanine nucleotide binding ability was inhibited after $5 \mathrm{~min}$ of incubation of either $\mathrm{T}_{\alpha}$ or $\mathrm{T}_{\beta \gamma}$ with $5 \mathrm{mM}$ EDC (data not shown). 


\section{DISCUSSION}

The role of the acidic residues of $T$ was evaluated by chemical labeling with DCCD and EDC, two carbodiimides differing in polarity. The function of $\mathrm{T}$ was only slightly affected by DCCD, which is hydrophobic in nature. On the contrary, EDC, which is hydrophilic and will aim at accessible carboxyl groups located on the surface of the protein, completely abolished the lightdependent guanine nucleotide binding activity of $T$. Since the chemical functionality is the same for both compounds, the dissimilar behaviors observed between DCCD- and EDC-treated $T$ must be directly related to the hydrophobicity and hydrophilicity of the reagents, which will target amino acids located on different regions of the protein.

There are several possible reaction pathways for the interaction of carbodiimides with carboxyl groups on proteins. The reaction of a carbodiimide

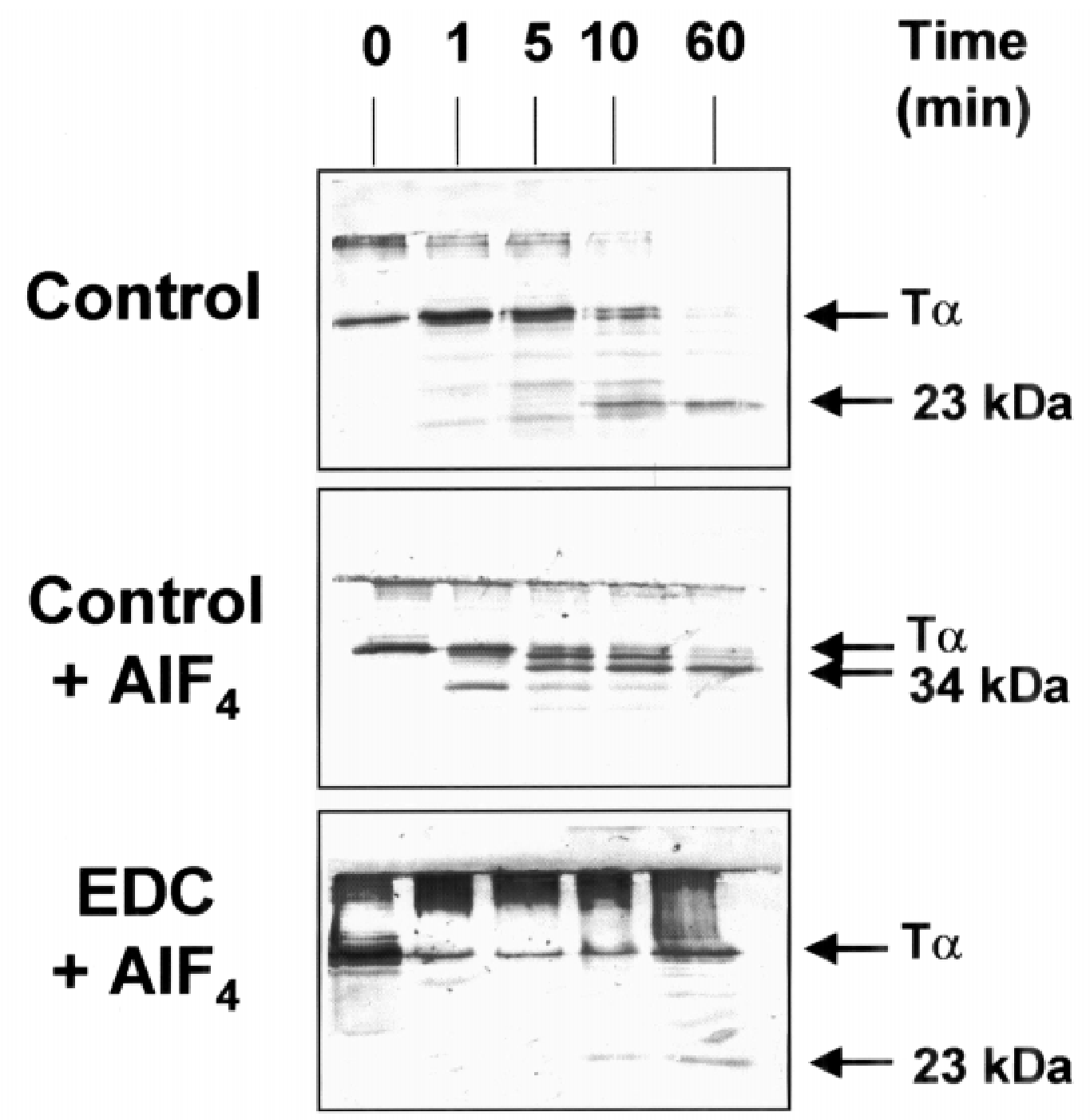

Figure 5.- Limited proteolysis studies of the conformation of untreated and EDC-treated T. At the indicated time intervals, the resulting fragments were resolved by SDS-PAGE and visualized by immunoblotting with anti-T polyclonal antibodies that preferentially recognize $T_{\alpha}$. When $T$ is in the inactive conformation, $T_{\alpha}-$ GDP is cleaved by trypsin into a fragment of $23 \mathrm{kDa}$ (Control). By contrast, when $\mathrm{T}$ is activated by fluoroaluminate, $\mathrm{T}_{\alpha}-\mathrm{GDP}-\mathrm{AlF}_{4}-$ is cleaved into a fragment of $34 \mathrm{kDa}$ that resist further proteolysis $\left(\right.$ Control $\left.+\mathrm{AlF}_{4}\right)$. The tryptic pattern of EDC-modified $\mathrm{T}$, following the addition of fluoroaluminate, is similar to that observed for the inactive conformation of $\mathrm{T}\left(\mathrm{EDC}+\mathrm{AlF}_{4}\right)$. 

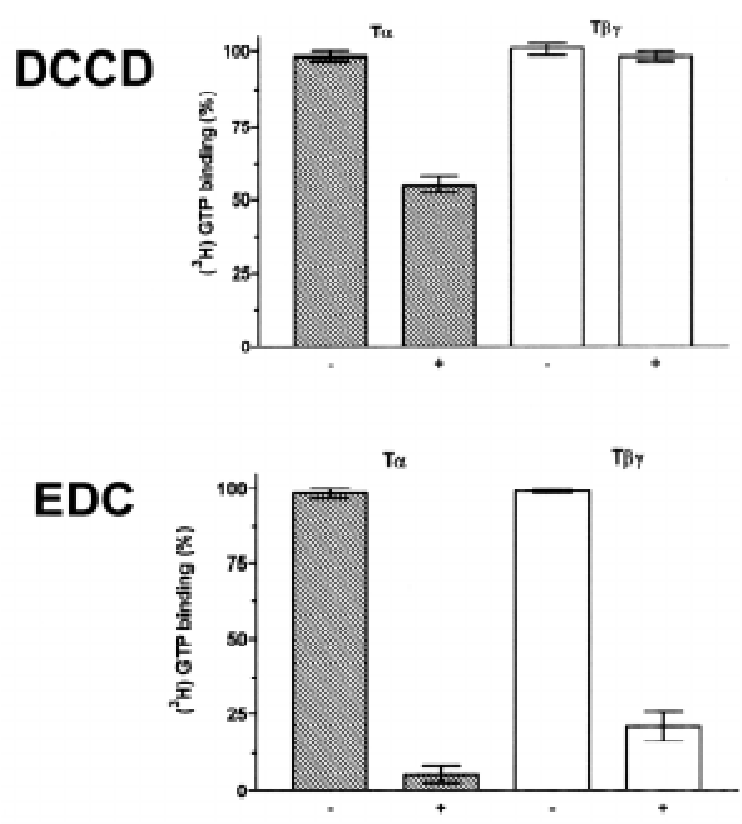

Figure 6.- GMPpNp binding activity of $T$ reconstituted by combining one functional unit modified with DCCD or EDC and the other one in its native state. $\mathrm{T}_{\alpha}$ or $\mathrm{T}_{\beta \gamma}$ was incubated with (+) or without (-) $5 \mathrm{mM} \mathrm{DCCD}$ or EDC, for $1 \mathrm{~h}$, at $4{ }^{\circ} \mathrm{C}$. Aliquots of the reaction mixtures were terminated with 30 $\mathrm{mM}$ Asp and analyzed for their remaining GMPpNp binding activity following reconstitution of the holoenzyme with the complementary untreated unit.

with an acidic residue may produce a stable $\mathrm{N}$-acylurea adduct, after the initial formation of an $\mathrm{O}$-acylurea intermediate. Alternatively, the $\mathrm{O}$-acylurea that is formed may interact with a nucleophile present in the buffer solution. If, however, the nucleophile is a nearby amino group of an amino acid side chain, an intermolecular or intramolecular "zero-length" cross-link may be formed (Toner-Webb and Taylor, 1987). Treatment of $T$ with EDC resulted in the formation of intermolecular covalently cross-linked oligomers of $>200$ $\mathrm{kDa}$. These high molecular weight species could be partially responsible for the inactivation of EDC-treated $\mathrm{T}$ samples. Results from non-denaturing gel electrophoresis and analytical ultracentrifugation have suggested the presence of oligomeric states of $\mathrm{T}$ and its subunits (Baehr et al., 1982). Consistent with these findings are kinetic studies of the $\mathrm{R}$ catalyzed guanine nucleotide exchange (Wessling-Resnick and Johnson, 1987a), as well as binding studies between $\mathrm{R}$ and $\mathrm{T}$
(Wessling-Resnick and Johnson, 1987b; Willardson et al., 1993), which demonstrate allosteric regulation of the interaction of $\mathrm{T}$ with $\mathrm{R}^{*}$. The molecular basis for the positive cooperative behavior was hypothesized to involve oligomeric associations of T. The EDC-induced crosslinking of $\mathrm{T}$ also provides physical evidence for the existence of these oligomers under native conditions. Similar results have been previously reported by trapping $\mathrm{T}$ oligomers using bifunctional maleimides (Millán and Bubis, 2002). In a membrane environment where the concentration of macromolecules is high, the kinetics of interactions between receptor and $\mathrm{G}$-protein is likely to be diffusion-limited. Formation of multimeric complexes of $\mathrm{T}$ would overcome the limitation by allowing a single $\mathrm{R}$ to interact with a locally concentrated pool of $T_{\alpha}$ subunits and thereby attain rapid signal amplification. Some G-protein-coupled receptors have been found to dimerize and oligomerize, in some cases forming complexes with structurally different Gprotein-coupled receptors (Bockaert and Pin, 1999; Salahpour et al., 2000). Evidently, the formation of $\mathrm{R}$ dimers and oligomers will also facilitate the amplification of the light response. However, for R, within intact functioning rods, the light-induced change in the diffusional speed of the activated receptor expected when it dimerizes or oligomerizes with other $\mathrm{R}$ molecules was not observed (Downer and Cone, 1985).

As illustrated in Figure 7, the modification of $\mathrm{T}$ with EDC blocked the productive interaction of $\mathrm{T}$ to $\mathrm{R}^{*}(\mathrm{a} \rightarrow \mathrm{b})$. In view of the fact that physical contact between $\mathrm{R}^{*}$ and $T$ represents the initial requirement for the T nucleotide exchange reaction to occur, the EDC-caused inactivation in GMPpNp binding activity can be attributed to hindrance at this step of the pathway. Since no effect was observed on the ability of EDC-treated $\mathrm{R}$ to activate $\mathrm{T}$, it appears that EDC introduces structural changes in the general folding of $\mathrm{T}$ that either prevent sterically its direct binding to $\mathrm{R}^{*}$ or physically hinder the conformational changes in this protein that are required to bind to $\mathrm{R}^{*}$. Several regions of $\mathrm{T}$ have been 
implicated in R contact (Hamm et al., 1988; García et al., 1995; Osawa and Weiss, 1995; Kisselev et al., 1994, 1995, 1999; Martin et al., 1996; Mazzoni and Hamm, 1996; Lichtarge et al., 1996). Other studies have also indicated that specific regions and residues located at the $\mathrm{C}$-terminal domain of $\mathrm{T}_{\alpha}$ interact with $\mathrm{R}^{*}$ (Onrust et al., 1997; Fahmy, 1998; Nishimura et al., 1998; Bubis et al., 2001). Yang et al. (1999) noticed that conformational changes taking place at the C-termini of $\mathrm{T}_{\alpha}$, during $\mathrm{G}$ protein activation might be important for allosteric communication between receptor binding and GDP-binding sites on the molecule. Furthermore, synthetic peptides from the $\mathrm{C}$ termini of $\mathrm{T}_{\alpha}$ and $\mathrm{T}_{\gamma}$, recognize $\mathrm{R}^{*}$ with similar affinity and can replace the holoprotein in stabilizing the active metarhodopsin II photointermediate. Interestingly, although both C-terminal regions of $\mathrm{T}_{\alpha}$ and $\mathrm{T}_{\gamma}$ have been localized to a common surface of $\mathrm{T}$ by $\mathrm{X}$-ray studies (Lambright et al., 1996), the distance between these two regions in GDP-bound T appears to be too long to interact with the same site in $\mathrm{R}$. This suggests that the signal transfer from $R^{*}$ to $T$ takes place by a twosite sequential mechanism in which nucleotide exchange catalysis relies on the
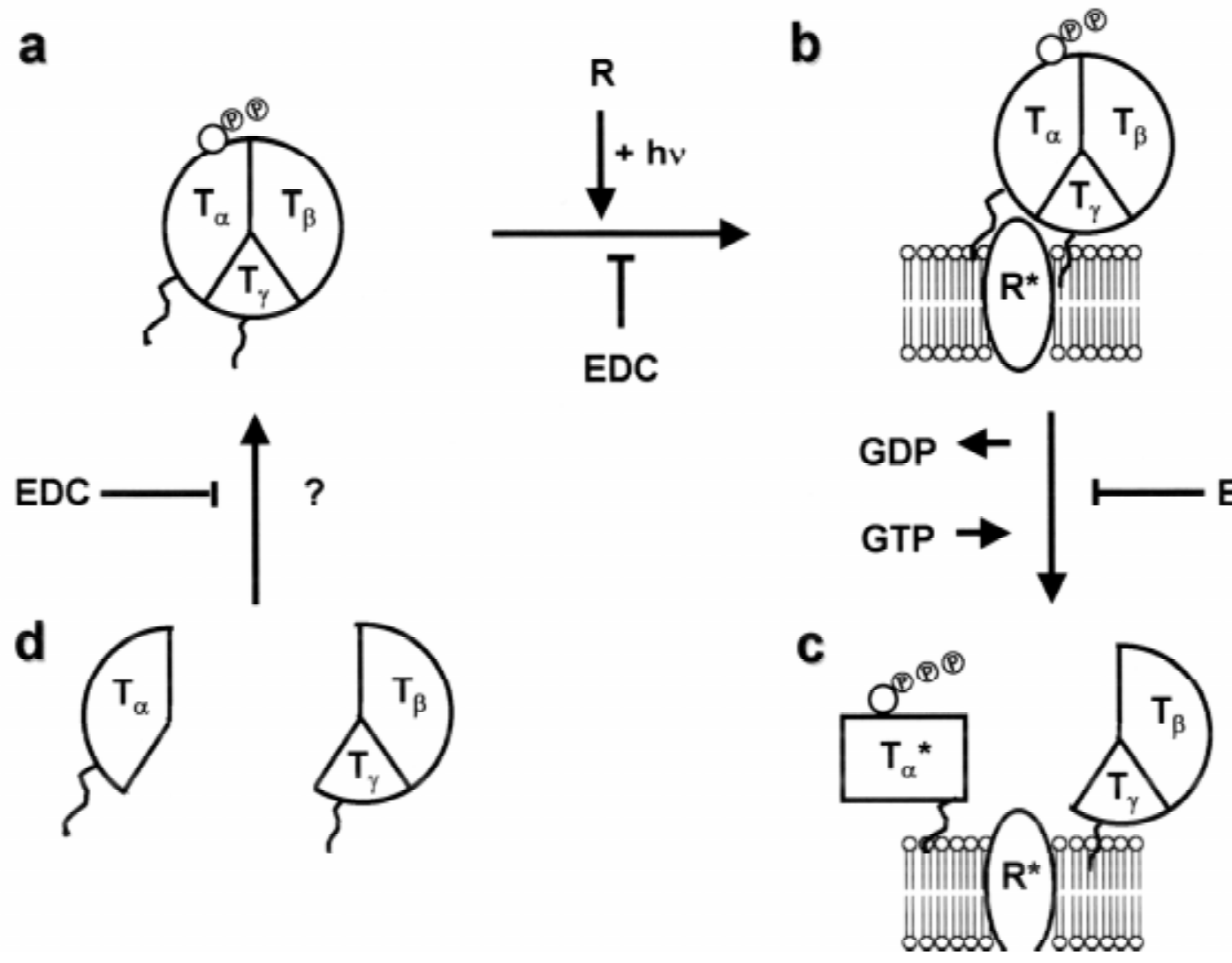

Figure 7.- Effects of EDC on the R and guanine nucleotide binding activities of T. The figure presents a summary of the specific points where EDC affects the functional interactions of $\mathrm{T}$. (a) The GDP-bound heterotrimeric $\mathrm{T}$ with its three subunits $\left(\mathrm{T}_{\alpha}, \mathrm{T}_{\beta}\right.$, and $\mathrm{T}_{\gamma}$ ). (b) The interactions of $\mathrm{T}$ with $\mathrm{R}^{*}$ and the membrane lipid bilayer. The acyl groups of $\mathrm{T}_{\alpha}$ and $\mathrm{T}_{\gamma}$ are shown interacting with the membrane. The modification of $T$ with EDC inhibits its light-dependent binding to $\mathrm{R}(\mathrm{a} \rightarrow \mathrm{b})$. (c) R catalyzes the GDP/ GTP exchange reaction on $T_{\alpha}$. GTP binding leads to dissociation of $T_{\alpha}$-GTP from the $T_{\beta \gamma}$ dimer. Treatment of $T$ with EDC hindered its guanine nucleotide exchange reaction $(\mathrm{b} \rightarrow \mathrm{c})$. (d) The functional units of $\mathrm{T}, \mathrm{T}_{\alpha}$ and $\mathrm{T}_{\beta \gamma}$, can be chromatographycally separated and then recombined to reconstitute the holoprotein (Bubis, 1995). Since EDC-modified $\mathrm{T}_{\alpha}$ was incapable of reassociating with intact $\mathrm{T}_{\beta \gamma}$, and EDC-treated $\mathrm{T}_{\beta \gamma}$ was not able to reattach to native $\mathrm{T}_{\alpha}$, EDC may also block intersubunit interactions $(\mathrm{d} \rightarrow \mathrm{a}) . *=$ Activated state. $\mathrm{O}_{\mathrm{P} P \mathrm{P})}=\mathrm{GTP}, \mathrm{O}_{\mathrm{P} P}=\mathrm{GDP}, \mathrm{h} v=$ light. 
geometry of interaction in matching pairs of at least two sites between $\mathrm{R}$ and $\mathrm{T}$ (Kisselev et al., 1999). Plausibly, the modification by EDC of acidic residues located in any of these $\mathrm{T}$ functional sites will prevent the successful association of the protein with $\mathrm{R}$.

In order to explore the ability of $\mathrm{R}$ to protect against the inactivation observed in $\mathrm{T}$ function, chemical modifications with EDC were carried out on preformed T:R* complexes. Functional assays performed on EDC-treated T: $R^{*}$ samples showed that $\mathrm{R}^{*}$ only partially protected against the inactivation of $\mathrm{T}$ by EDC and suggested that other Asp and/or Glu residues not involved in the interaction with $\mathrm{R} *$ were also labeled in $\mathrm{T}$ by EDC. Trypsin protection assays of $\mathrm{T}$, in the presence of fluoroaluminate, have been employed to measure the ability of $\mathrm{T}$ to undergo a conformational change to the active state in a light-independent manner. Since no trypsin protection was observed when $\mathrm{AlF}_{4}$ was added to EDC-labeled T, some of the residues modified by EDC in the protein must be located in regions that will sterically hinder the GTP/GDP exchange induced by $\mathrm{R}^{*}$, preventing either the exit of GDP or the uptake of GTP (Fig. 7, b $\rightarrow$ c). Therefore EDC must also modify acidic amino acids located either close to the magnesium and guanine nucleotide binding pocket of $\mathrm{T}$, or in the switch regions that undergo the conformational changes occurring during the light-induced activation of the protein. As shown by crystallographic analyses (Sprang, 1997), five highly-conserved elements, designated G-1 through G-5, some of which contain acidic residues, outline the guanine nucleotide-binding site and define the 3Dstructure of the proteins belonging to the GTPase superfamily. The diphosphatebinding loop (G-1) with the consensus sequence GXXXXGK(S/T), contacts the $\alpha$ and $\beta$-phosphates of the guanine nucleotide. The G-2 loop (XTX) contains a conserved threonine residue involved in $\mathrm{Mg}^{2+}$ coordination. A DXXG sequence, G-3, links the subsites for binding of $\mathrm{Mg}^{2+}$ and the $\gamma$ phosphate of GTP. The guanine ring is partially recognized by the conserved
NKXD sequence (G-4). Finally, the G-5 box with consensus sequence $(\mathrm{T} / \mathrm{G})(\mathrm{C} / \mathrm{S}) \mathrm{A}$, buttresses the guanine base recognition site. Additionally, a view of all threedimensional structures of $\mathrm{T}_{\alpha}$ (Noel et al., 1993; Lambright et al., 1994; Sondek et al., 1994) showed that several acidic residues were involved directly either in the coordination of $\mathrm{Mg}^{+2}$, in guanine nucleotide binding, or in the mechanism for GTP hydrolysis. The labeling by EDC of any of these potential targets will probably yield the inactivation observed in the EDC-treated T sample. Moreover, the structural differences between inactive and active $\mathrm{T}_{\alpha}$, induced by nucleotide exchange, are localized to three adjacent regions referred as switch I $\left(\operatorname{Ser}_{173}-\mathrm{Thr}_{183}\right)$, switch II $\left(\mathrm{Phe}_{195}-\mathrm{Thr}_{215}\right)$, and switch III $\left(\mathrm{Asp}_{227^{-}}\right.$ $\operatorname{Arg}_{238}$ ) (Lambright et al., 1994), which also contain residues of the type characterized in this manuscript. The modification of carboxyl groups located in the switch regions of $\mathrm{T}_{\alpha}$ will most likely hinder the conformational changes induced in the protein by GTP and will also cause the inactivation of $\mathrm{T}$.

When $\mathrm{T}_{\alpha}$ or $\mathrm{T}_{\beta \gamma}$ was individually incubated with EDC and then combined with the intact complementary unit in order to reform the holoenzyme, the guanine nucleotide binding activity of the reconstituted protein was also completely inhibited. As with $\mathrm{T}$, the hindrance of steps $\mathrm{a} \rightarrow \mathrm{b}$ and $\mathrm{b} \rightarrow \mathrm{c}$ will substantiate the inactivation of EDC-labeled $\mathrm{T}_{\alpha}$ and EDClabeled $\mathrm{T}_{\beta \gamma}$. However, if EDC is modifying acidic residues involved in inter-subunit contacts, the labeling of the individual $\mathrm{T}$ units with EDC may also prevent the reconstitution of a functional holoenzyme (Fig. 7, d $\rightarrow$ a). Consistent with this, several acidic residues have been implicated in maintaining the $\mathrm{T}_{\alpha}-\mathrm{T}_{\beta}$ interfaces by ion pair interactions (Lambright et al., 1996). In addition, single Ala mutations in amino acids of $\mathrm{T}_{\beta}$ that contact $\mathrm{T}_{\alpha}$, which included two Asp residues ( $\mathrm{Asp}_{186}$ and $\mathrm{Asp}_{228}$ ), blocked R*-mediated GTP/GDP exchange, and suggested an active participation of $\mathrm{T}_{\beta}$ in receptor-catalyzed nucleotide exchange (Ford et al., 1998). 
Similar to $\mathrm{T}, \mathrm{T}_{\beta \gamma}$ was almost not affected by DCCD. In contrast, the holoenzyme reconstituted with DCCD-modified $\mathrm{T}_{\alpha}$ and native $\mathrm{T}_{\beta \gamma}$ showed approximately $50 \%$ inhibition on its guanine nucleotide binding activity. We believe that Asp and/or Glu residues located in the proximity of the metal and nucleotide interaction sites in $\mathrm{T}_{\alpha}$, are most likely the best targets for DCCD labeling. Guanine nucleotide binding sites contain a hydrophobic pocket that constitutes the primary recognition site for the guanine ring. Since $\mathrm{Mg}^{+2-G D P}$ is strongly bound to purified $\mathrm{T}$, the metalnucleotide complex may protect against DCCD inactivation, explaining the lack of effect of DCCD on the holoenzyme. On the other hand, $\mathrm{T}_{\alpha}$ is purified free of nucleotide from the blue agarose column (Shichi et al., 1984; Bubis, 1995). In this case, the acidic residues involved in the GTP binding pocket will be more susceptible to DCCDlabeling. In spite of this, $\mathrm{T}_{\alpha}$ was always stored and maintained in buffers containing $\mathrm{Mg}^{+2}$, and the metal may be protecting to some extent against the modification by DCCD. The labeling by DCCD of any of the target residues directly involved in the coordination of magnesium, in nucleotide binding, or in the mechanism for GTP hydrolysis, may cause the partial inactivation observed in DCCD-modified $\mathrm{T}_{\alpha}$. Furthermore, the labeling of $\mathrm{T}_{\alpha}$ with DCCD may also be affecting its interaction with $\mathrm{T}_{\beta \gamma}$, hindering the reformation of the holoenzyme.

\section{ACKNOWLEDGMENTS}

This work was supported by a grant from FONACIT, N ${ }^{\circ}$ S1-2000000514, Caracas, Venezuela.

\section{REFERENCES}

BAEHR W, DEVLIN MJ, APPLEBURY ML (1979) Isolation and characterization of cGMP phosphodiesterase from bovine rod outer segments. J Biol Chem 254: 11669-11677

BAEHR W, MORITA EA, SWANSON RJ, APPLEBURY ML (1982) Characterization of bovine rod outer segment G-protein. J Biol Chem 257: 6452-646
BIGAY J, DETERRE P, PFISTER C, CHABRE M (1985) Fluoroaluminates activate transducin-GDP by mimicking the gamma-phosphate of GTP in its binding site. FEBS Lett 191: 181-185

BIGAY J, DETERRE P, PFISTER C, CHABRE M (1987) Fluoride complexes of aluminium or beryllium act on G-proteins as reversibly bound analogues of the gamma phosphate of GTP. EMBO J 6: 2907-2913

BOCKAERT J, PIN JP (1999) Molecular tinkering of G protein-coupled receptors: an evolutionary success. EMBO J 18: 1723-1729

BRADFORD MM (1976) A rapid and sensitive method for the quantitation of microgram quantities of protein utilizing the principle of protein-dye binding. Anal Biochem 72: 248-254

BUBIS J (1995) Improved purification of transducin subunits from bovine retinal rod outer segments. Biol Res 28: 291-299

BUBIS J (1998) Effect of detergents and lipids on transducin photoactivation by rhodopsin. Biol Res 31: $59-71$

BUBIS J, KHORANA HG (1990) Sites of interaction in the complex between $\beta$ - and $\gamma$-subunits of transducin. J Biol Chem 265: 12995-12999

BUBIS J, MILLAN EJ, MARTINEZ R (1993) Identification of guanine nucleotide binding proteins from Trypanosoma cruzi. Biol Res 26: 177-188

BUBIS J, ORTIZ JO, MÖLLER C, MILLÁN EJ (1995) Identification and characterization of transducin functional cysteines, lysines, and acidic residues by group-specific labeling and chemical cross-linking. In: ATASSI MZ, APPELLA E (eds) Methods in Protein Structure Analysis. New York: Plenum Press Pp: 227-250

BUBIS J, ORTIZ JO, MÖLLER C (2001) Chemical modification of transducin with iodoacetic acid: transducin- $\alpha$ carboxymethylated at $\mathrm{Cys}_{347}$ allows transducin binding to light-activated rhodopsin but prevents its release in the presence of GTP. Arch Biochem Biophys 395: 146-157

CLERC A, CATTY P, BENNETT N (1992) Interaction between cGMP-phosphodiesterase and transducin $\alpha$ subunit in retinal rods. A cross-linking study. J Biol Chem 267: 19948-19953

DHANASEKARAN N, WESSLING-RESNICK M, KELLEHER DJ, JOHNSON GL, RUOHO AE (1988) Mapping of the carboxyl terminus within the tertiary structure of transducin's $\alpha$ subunit using the heterobifunctional cross-linking reagent, 125I-N-(3iodo-4-azidophenylpropionamido-S-(2-thiopyridyl) cysteine. J Biol Chem 263: 17942-17950

DOWNER NW, CONE RA (1985) Transient dichroism in photoreceptor membranes indicates that stable oligomers of rhodopsin do not form during excitation. Biophys J 47: 277-284

FAHMY K (1998) Binding of transducin and transducinderived peptides to rhodopsin studies by attenuated total reflection-Fourier transform infrared difference spectroscopy. Biophys J 75: 1306-1318

FORD CE, SKIBA NP, BAE H, DAAKA Y, REUVENY E, SHEKTER LE, ROSAL R, WENG G, YANG C-S, IYENGAR R, MILLER RJ, YAN LY, LEFKOWITZ RJ, HAMM HE (1998) Molecular basis for interactions of $G$ protein $\beta \gamma$ subunits with effectors. Sci 280 : 1271-1274 
FUNG BK-K (1983) Characterization of transducin from bovine retinal rod outer segments. I. Separation and reconstitution of the subunits. J Biol Chem 258: 1049510502

FUNG BK-K, NASH CR (1983) Characterization of transducin from bovine retinal rod outer segments. II. Evidence for distinct binding sites and conformational changes revealed by limited proteolysis with trypsin. J Biol Chem 258: 10503-10510

GARCIA PD, ONRUST R, BELL SM, SAKMAR TP, BOURNE HR (1995) Transducin- $\alpha$ C-terminal mutations prevent activation by rhodopsin: a new assay using recombinant proteins expressed in cultured cells. EMBO J 14: 4460-4469

HAMM HE (1998) The many faces of G protein signaling. J Biol Chem 273: 669-672

HAMM HE, DERETIC D, ARENDT A, HARGRAVE PA, KOENIG B, HOFMANN KP (1988) Site of G protein binding to rhodopsin mapped with synthetic peptides from the $\alpha$ subunit. Sci 241: 832-835

HINGORANI VN, HO Y-K (1987) Chemical modification of bovine transducin: effect of fluorescein $5^{\prime}$ isothiocyanate labeling on activities of the transducin $\alpha$ subunit. Biochem 26: 1633-1639

HINGORANI VN, TOBIAS DT, HENDERSON JT, HO YK (1988) Chemical cross-linking of bovine retinal transducin and cGMP phosphodiesterase. J Biol Chem 263: 6916-6926

HO Y-K, FUNG BK-K (1984) Characterization of transducin from bovine retinal rod outer segments. The role of sulfhydryl groups. J Biol Chem 259: 6694-6699

HOFMANN KP, REICHERT J (1985) Chemical probing of the light-induced interaction between rhodopsin and G-protein. Near-infrared light-scattering and sulfhydryl modifications. J Biol Chem 260: 7990-7995

JAFFÉ M, BUBIS J (2002) Affinity labeling of the guanine nucleotide binding site of transducin by pyridoxal 5'phosphate. J Prot Chem 21: 339-348

KISSELEV OG, ERMOLAEVA MV, GAUTAM N (1994) A farnesylated domain in the $G$ protein $\gamma$ subunit is a specific determinant of receptor coupling. J Biol Chem 269: 21399-21402

KISSELEV O, PRONIN A, ERMOLAEVA M, GAUTAM $\mathrm{N}$ (1995) Efficient interaction with a receptor requires a specific type of prenyl group on the $\mathrm{G}$ protein $\gamma$ subunit. Proc Natl Acad Sci. USA 92: 9102-9106

KISSELEV OG, MEYER CK, HECK M, ERNST OP, HOFMANN KP (1999) Signal transfer from rhodopsin to the G-protein: evidence for a two-site sequential fit mechanism. Proc Natl Acad Sci USA 96: 4898-4903

KÜHN H (1980) Light- and GTP-regulated interaction of GTPase and other proteins with bovine photoreceptor membranes. Nature 283: 587-589

LAEMMLI UK (1970) Cleavage of structural proteins during assembly of head bacteriophage T4. Nature 227: 680-685

LAMBRIGHT DG, NOEL JP, HAMM HE, SIGLER PB (1994) Structural determinants for activation of the $\alpha$-subunit of a heterotrimeric G protein. Nature 369: 621-628

LAMBRIGHT DG, SONDEK J, BOHM A, SKIBA NP, HAMM HE, SIGLER PB (1996) The $2.0 \AA$ crystal structure of a heterotrimeric $G$ protein. Nature 379 : 311-319
LICHTARGE O, BOURNE HR, COHEN FE (1996) Evolutionarily conserved G $\alpha \beta \gamma$ binding surfaces support a model of the G protein-receptor complex. Proc Natl Acad Sci USA 93: 7507-7511

MARTIN EL, RENS-DOMIANO S, SCHATZ PJ, HAMM HE (1996) Potent peptide analogues of a G protein receptor-binding region obtained with a combinatorial library. J Biol Chem 271: 361-366

MAZZONI MR, HAMM HE (1996) Interaction of transducin with light-activated rhodopsin protects it from proteolytic digestion by trypsin. J Biol Chem 271: 30034-30040

MILLÁN EJ, BUBIS J (2002) Identification of functionally important cysteines in the $\alpha$-subunit of transducin by chemical cross-linking techniques. J Protein Chem 21: $1-8$

NATOCHIN M, ARTEMYEV NO (2000) Mutational analysis of functional interfaces of transducin. Meth Enzymol 315: 539-554

NISHIMURA S, KANDORI H, MAEDA A (1998) Interaction between photoactivated rhodopsin and the C-terminal peptide of transducin a-subunit studied by FTIR spectroscopy. Biochem 37: 15816-15824

NOEL JP, HAMM HE, SIGLER PB (1993) The $2.2 \AA$ crystal structure of transducin- $\alpha$ complexed with GTP $\gamma$ S. Nature 366: 654-663

ONRUST R, HERZMARK P, CHI P, GARCIA PD, LICHTARGE O, KINGSLEY C, BOURNE HR (1997) Receptor and $\beta \gamma$ binding sites in the a subunit of the retinal $G$ protein transducin. Science 275: 381-384

ORTIZ JO, BUBIS J (2001) Effects of differential sulfhydryl group-specific labeling on the rhodopsin and guanine nucleotide binding activities of transducin. Arch. Biochem Biophys 387: 233-242

OSAWA S, WEISS ER (1995) The effect of carboxylterminal mutagenesis of Gta on rhodopsin and guanine nucleotide binding. J Biol Chem 270: 31052-31058

PUGH EN Jr, NIKONOV S, LAMB TD (1999) Molecular mechanisms of vertebrate photoreceptor light adaptation. Curr Opin Neurobiol 9: 410-418

REICHERT J, HOFMANN KP (1984) Sulfhydryl group modification of photoreceptor G-protein prevents its light-induced binding to rhodopsin. FEBS Lett 168: 121-124

SALAHPOUR A, ANGERS S, BOUVIER M (2000) Functional significance of oligomerization of Gprotein-coupled receptors. Trends Endocrin Metab 11: $163-168$

SHICHI H, SOMERS RL (1978) Light-dependent phosphorylation of rhodopsin. Purification and properties of rhodopsin kinase. J Biol Chem 253: 7040-7046

SHICHI H, YAMAMOTO K, SOMERS RL (1984) GTP binding protein: properties and lack of activation by phosphorylated rhodopsin. Vision Res 24: 1523-1531

SONDEK J, LAMBRIGHT DG, NOEL JP, HAMM HE, SIGLER PB (1994) GTPase mechanism of Gproteins from the $1.7-\AA$ crystal structure of transducin $\alpha$ GDP-AIF ${ }_{4}^{-}$. Nature 372, 276-279

SPRANG SR (1997) G protein mechanisms: insights from structural analysis. Annu Rev Biochem 66: 639-678

TONER-WEBB J, TAYLOR SS (1987) Inhibition of the catalytic subunit of cAMP-dependent protein kinase by dicyclohexylcarbodiimide. Biochem 26: 7371-7378 
TOWBIN H, STAEHELIN T, GORDON J (1979) Electrophoretic transfer of proteins from polyacrylamide gels to nitrocellulose sheets: Procedure and some applications. Proc Natl Acad Sci USA 76: 4350-4354

WALD G, BROWN P (1953) The molar extinction of rhodopsin. J Gen Physiol 37: 189-200

WESSLING-RESNICK M, JOHNSON GL (1987a) Allosteric behavior in transducin activation mediated by rhodopsin. Initial rate analysis of guanine nucleotide exchange. J Biol Chem 262: 3697-3705
WESSLING-RESNICK M, JOHNSON GL (1987b) Transducin interactions with rhodopsin. Evidence for positive cooperative behavior. J Biol Chem 262: 12444-12447

WILLARDSON BM, POU B, YOSHIDA T, BITENSKY MW (1993) Cooperative binding of the retinal rod Gprotein, transducin, to light-activated rhodopsin. J Biol Chem 268: 6371-6382

YANG C-S, SKIBA NP, MAZZONI MR, HAMM HE (1999) Conformational changes at the carboxyl terminus of $\mathrm{G} \alpha$ occur during $\mathrm{G}$ protein activation. $\mathrm{J}$ Biol Chem 274: 2379-2385 